\title{
Hypertrophic scars and keloids: a review and current treatment modalities
}

\author{
Sanjeev Tripathi ${ }^{1}$, Kumud Soni ${ }^{1}$, Poornima Agrawall ${ }^{1}$, Vishal Gour ${ }^{1}$, Rajesh Mondal ${ }^{2}$ and Vandana Soni ${ }^{1 *}$ (D)
}

\begin{abstract}
Hypertrophic scars (HTS) are raised, red, rigid, inflexible cell-like, and cosmetic problems precipitated due to multiple underlying dermal injuries such as burn, surgery, and trauma during which aberrant wound healing with more pathological deposition of the extracellular matrix than degradation leads to their spawning. Till date, well established and specific treatments for HTS have not been reported; hence, the need of recent developments is thrusted with novel drug delivery vision. This review will try to encompass all the agogs to HTS, definition, pathophysiology, mechanism of hypertrophic scar formation, the role of growth factors in hypertrophic scarring, and their difference with keloids. Further, it will illuminate the available medicaments and recent advances in novel topical drug delivery systems such as ethosomes, transethosomes, liposomes, solid lipid nanoparticles, and microsponges for treatment of HTS.
\end{abstract}

Keywords: Hypertrophic scar, Wound healing, Endocrinological hypothesis, Role of growth factors, Role of HMGB1 in HTS, Topical Novel DDS

\section{Introduction}

Scar is a cutaneous development in the skin, culminated by biological wound healing processes. The skin restores the lost tissues by scarring where the new cell population resides in a newly constructed connective tissue with a new vasculature. The chemical components of a scar remain similar to intact the skin, although the organization of those components differs from that of the normal dermis. This inability to reassemble original tissues like that of the dermis describes a scar (Ehrlich and Krummel 1996). Actual cause behind disposing of this phenomenon lies in certain critical paradigms of wound healing where the transformation of a wound clot into a granulation tissue hinges on the delicate balance of extracellular matrix proteins deposition and degradation rhythmically, and when this process is disrupted, abnormalities in natural scarring appear, resulting in either keloid or hypertrophic scar formation (Gauglitz et al. 2011a, 2011b). This lack of complete

\footnotetext{
* Correspondence: drvandanasoni@gmail.com

${ }^{1}$ Department of Pharmaceutical Sciences, Dr. Harisingh Gour University, Sagar 470 003, (M.P.), India

Full list of author information is available at the end of the article
}

healing prior to the development of fibrous connective tissues due to slapdashed arrangement of extracellular matrix proteins leads to hypertrophic scars (HTS) or keloids. These HTS and keloids are identified by hypervascularity and pathological deposition of extracellular matrix (ECM) components (Zhao et al. 2017). This review shall mainly shed light on these two types of scars, HTS and keloids.

\section{HTS}

A HTS is a film, raised within the site of injury, occasionally symptomatic, demonstrate fine, thin wavy, systematically arranged, and parallel-oriented collagen fibers and bundles (Tuan and Nichter 1998). It takes over 4 to 8 weeks after injury for their development and usually appears over areas of high tension like extensor joints (Zhu et al. 2016). Although their development may take years, they tend to regress over time. These HTS express high levels of low-density dermatan sulfate proteoglycans only (Ghazawi et al. 2018).

(c) The Author(s). 2020 Open Access This article is licensed under a Creative Commons Attribution 4.0 International License, which permits use, sharing, adaptation, distribution and reproduction in any medium or format, as long as you give appropriate credit to the original author(s) and the source, provide a link to the Creative Commons licence, and indicate if changes were made. The images or other third party material in this article are included in the article's Creative Commons licence, unless indicated otherwise in a credit line to the material. If material is not included in the article's Creative Commons licence and your intended use is not permitted by statutory regulation or exceeds the permitted use, you will need to obtain permission directly from the copyright holder. To view a copy of this licence, visit http://creativecommons.org/licenses/by/4.0/. 


\section{Keloids}

Keloids are defined as fibrous structures that appear as tender growths, variably pruritic near the site of injuries, appearing around the age of 10 and 30. Mostly keloids have been sited around the anterior portion of the chest, upper back, shoulders, and earlobes. With their unknown etiology, the accumulated fibrous tissue is associated with increased metabolic activity and cellularity of keloid fibroblasts (Shaffer et al. 2002). They are composed of large amounts of both low-density chondroitin sulfate proteoglycans (PGs) and low-density dermatan sulfate proteoglycan (Kuehlmann et al. 2019). Inappropriate treatment problem is caused due to a lack of proper identification and differentiation between HTS and keloids (Miller and Nanchahal 2005), although HTS and keloids seem to be similar but can be differentiated on the spoors portrayed via clinical, histological, and epidemiological examination (Table 1).

\section{How abnormal wound healing promotes HTS and keloids}

The development of HTS or keloids involves a slapdash arrangement of proteins and a series of mishaps in the milieu of wound healing. Wound healing is a complex process, involving sequential participation of molecular factors such as fibroblast and profibroblast and a cascade of actions happening through illustrative steps like hemostasis, inflammation, proliferation, and tissue remodeling. Interaction among these processes results in the synthesis of collagen over the surface of the wound. On a contrary note, an alteration in these molecular factors, complex networks of pro-fibrotic, and anti-fibrotic molecules, such as growth factors, proteolytic enzymes, and ECM proteins may lead to the formation of HTS or keloids (Gale 2011). These HTS also involve a series of growth factors (TGF- $\beta$ family), cytokines, and interleukin (Santucci et al. 2001).

\section{Hemostasis}

Hemostasis is defined as the physiological process responsible for haulting bleeding at the site of an injury while keeping up the normal blood flow in the circulation. Blood loss is stopped by the formation of a

Table 1 HTS (HTS) vs keloids (Berman et al. 2017)

\begin{tabular}{lll}
\hline S.No. & Hypertrophic scar & Keloids \\
\hline 1 & Thin, well organized & Thick, uneven organized \\
2 & $\begin{array}{l}\text { Occurs in 4-5 weeks } \\
\text { after injury }\end{array}$ & Occurs in a year after surgery \\
3 & It is wavy-like structure & It is larger than hypertrophic scar \\
4 & Less vascularized dermis & Highly vascularized dermis \\
5 & $\begin{array}{l}\text { It is caused by trauma and } \\
\text { burns injuries }\end{array}$ & It is caused by minor injuries \\
\hline
\end{tabular}

hemostatic plug. The inner lining tissues of the blood vessels maintain an anticoagulatory surface that works to maintain blood's fluidity, but if the blood vessels are damaged, integrants of the subendothelial matrix are exposed to the blood. These diverse constituents activate two main cycles of hemostasis to initiate the formation of a blood clot, primarily platelets, and fibrin. This compactly perpetuated activation within seconds prevents blood loss at the site of injury.

Platelet aggregation and platelet plug formation make up to primary hemostasis. Platelets are activated in a sophisticated multifarious manner and result in adherence to the site of injury and to each other as well, plugging the gouged wound. Secondary hemostasis involves deposition of the insoluble fibrin, generated by the proteolysed coagulation cascade. This insoluble fibrin forms a mesh that is incorporated into and around the platelet plug which strengthens and stabilize the blood clot; this entire process of maintaining the balance gets disrupted in HTS development (Velnar et al. 2009).

\section{Inflammation}

An impaired inflammatory response to skin injury is implicated in the development of HTS and keloids. An immune response involving impaired modulations of fibrogenesis, in which type 1 T-helper cells (TH1) attenuate skin fibrosis through secretion of interleukin 12 (IL-12) and interferon, whereas TH2 cytokines secreted by CD4+ T cells such as IL-4, IL-5, IL-10, and IL-13 have been involved in the growth of keloids. Both the intensity and the type of immune response significantly contribute to abnormal scar formation. In fact, the dermis in both keloids and HTS is infiltrated by CD3+, $\mathrm{CD} 45 \mathrm{RO}+$, and HLA-antigen D-related CD4+ $\mathrm{T}$ cells, as well as CD1a+/CD36+/intercellular adhesion molecule positive dendritic cells (Yates et al. 2012). Aberrant cytokine secretion from chronic infiltration of immune cells in keloids significantly contributes to the development of pathogenic scars (Jester et al. 2012).

\section{Proliferation}

The proliferative phase can start as early as the first week after injury and can go up to 7 weeks. The hemostatic plug originally created at the time of injury is replaced by granulation tissue. The major components of granulation tissue are macrophages, fibroblasts, proteoglycans, hyaluronic acid, collagen, and elastin. Platelet-derived growth factors (PDGF) and TGF- $\beta$ released by macrophages activate fibroblasts and induce collagen III formation and the creation of an ECM (Gong et al. 2017). With the upregulation of vascular endothelial growth factors (VEGF), angiogenesis is also initiated during this phase. This exuberant response produces immature leaky blood vessels. The production of new blood vessels provides an environment 
with easy access to necessary nutrients, signals, and cells essential for coordinating repair (Huang et al. 2015).

\section{Tissue remodeling}

The remodeling phase can take up to a year to complete. As the wound matures, the delicate balance between apoptosis of existing cells and the production of new cells is propelled. An imbalance of this process is observed during the formation of HTS. During this phase, the granulation tissue previously produced is rearranged. Type III collagen is replaced by type I which results in a brawnier scar tissue development. However, the new type I collagen is arranged in bundles in the dermis differing from the basket weave orientation appreciated in an uninjured normal dermis (Zhu et al. 2016).

This new arrangement prevents the scar from obtaining the full strength of the original unscarred skin. The decrease in metabolic demand during this phase initiates the regression of the immature vessels created during the proliferation phase. In addition, myofibroblasts are activated to facilitate the contraction of the lesion. These actin-rich cells and reorganization of mature blood contribute to minimizing the surface area of the scar (Tanriverdi-Akhisaroglu et al. 2009) (Fig. 1).

\section{Mechanism of scar formation}

(A) Multiple causes of dermal injuries such as burn, surgery, and trauma trigger immune cells on aberrant wound healing. (B) Immune cell-like macrophages, mast cells, neutrophils, eosinophils, and $\mathrm{T}$ cells promote pathologic scar formation via enhancing inflammation at the site of injury. (C) Various growth factors like VEGF, PDGF stimulate chemotaxis, and cell functioning including cell proliferation, angiogenesis, re-epithelization, and stimulate fibrosis. (D) Migration and proliferation of different cell types such as keratinocytes, myofibroblasts, and mast cells increase, which play an indispensable role in signal transduction between paracrine secretion and epithelium matrix. In abnormal wound healing, myofibroblasts increase collagen synthesis and retard cell migration, thus resulting in excessive and rigid scarring. (E) With the assistance of keratinocytes and mast cells, proliferative fibroblasts produce massive collagen, which makes the extracellular matrix accumulate below the dermis, leading to scar formation.

\section{Role of plasminogen activator inhibitor-1 in HTS}

High levels of plasminogen activator inhibitor PAI-1 and low levels of vitamin $\mathrm{D}$ receptors (VDR) expression had

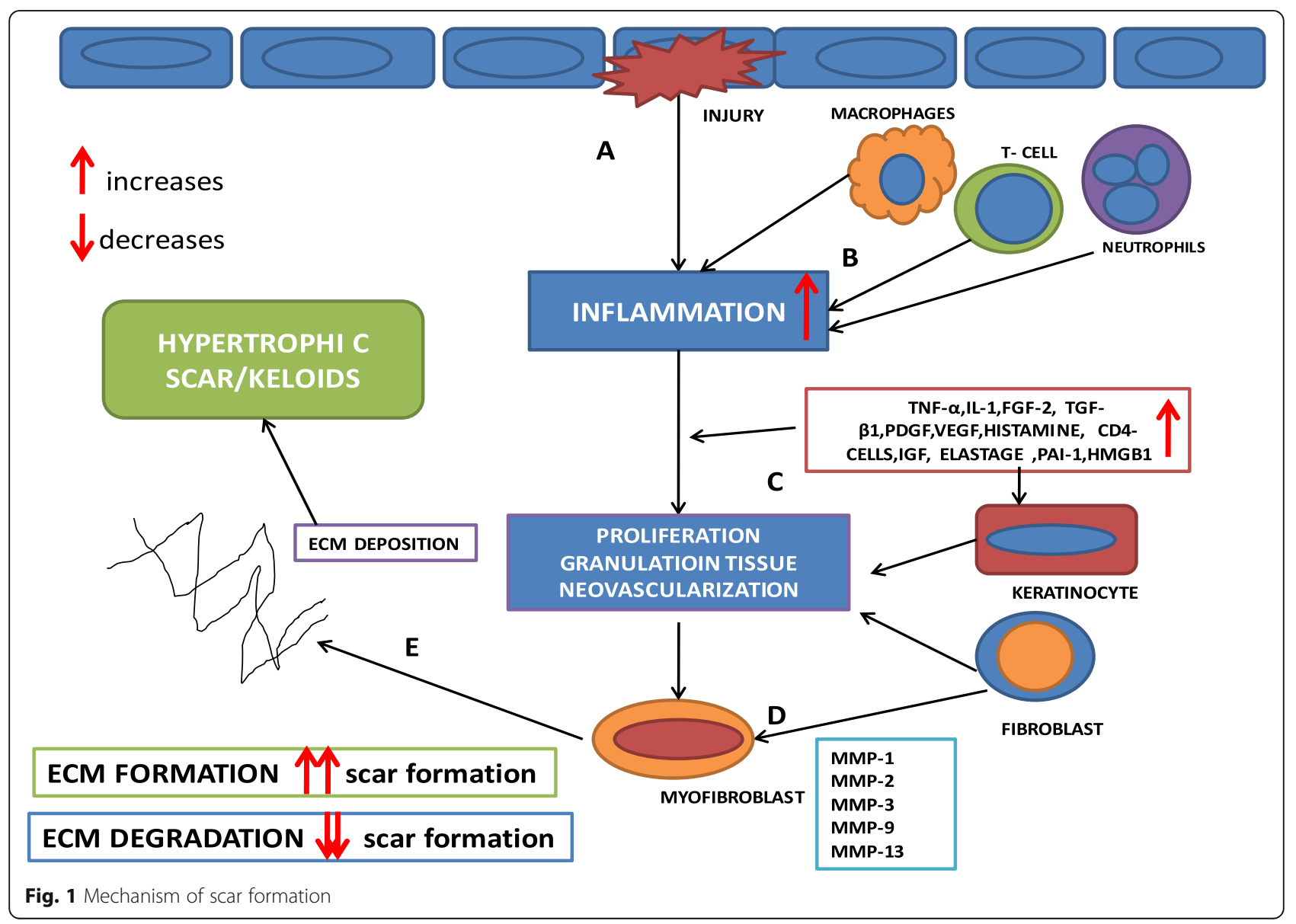


been found to be significantly associated with an increased risk for keloids (Fig. 2).

Plasminogen activator inhibitors-1(PAI-1) also called Serpine E1 a protein in nature inhibits collagen degradation. Elevated expression of PAI-1 inhibits the major plasminogen activators t-PA (tissue plasminogen activator) and u-PA(urokinase plasminogen activator); both activators convert plasminogen into plasmin and plasmin being major protease contributing in fibrinolysis and degradation of other glycoproteins in ECM (Mehta et al. 2016).

\section{Key growth factor pathways for HTS}

The key growth factors to be taken note in the pathophysiology of HTS are transforming growth factor- $\beta$ (TGF $\beta$ ), PDGF, connective tissue growth factor (CTGF), epidermal growth factor (EDGF), and VEGF (Zhao et al. 2017). Three isoforms of TGF identified in mammals are namely $\beta 1, \beta 2$, and $\beta 3$. TGF $\beta 1$ is thought to have different biological activity in wound healing. Both TGF $\beta 1$ and TGF $\beta 2$ stimulate fibrosis and increase scar formation. TGF $\beta 1$ promotes growth and collagen secretion and thus takes part in keloids formation, whereas TGF $\beta 3$ has been shown to be either scar inducing or reducing (Lichtman et al. 2016). VEGF is a more specific mitogen for endothelial cells. It assists in wound healing via binding to specific receptors VEGFRs on EPCs (pro-angiogenic endothelial progenitor cells). Angiogenesis allows new capillaries to provide nutrients to the wound and thus is critical for wound healing. Recent studies showed that VGEF promotes keloid and HTS formation (Wu et al. 2006). Research conducted using a rabbit model ensured the persistent upregulation of CTGF in HTS; it showed that CTGF had limited participation in the early dermal healing but was a key mediator of hypertrophic scar formation (Shi-Wen et al. 2008). CTGF antisense therapy had no measurable effects on early wound healing (Zhao et al. 2017). In HTS and keloids, fibroblasts have upregulation of CTGF transcription and an exaggerated capacity for CTGF transcription in response to TGF- $\beta$ stimulation, which suggested the blockage of CTGF activity, and further reduction of pathologic scar formation.

Platelet-derived growth factor (PDGF) family consists of 5 members structurally identified as a disulfide-linked dimeric protein composed of varying combinations of four polypeptide chains (A, B, C, and D) (Shin et al. 2015). PDGF stimulates multiple cellular mechanisms including chemotaxis, cell proliferation, inflammation, angiogenesis, and re-epithelization. PDGF appears to play an essential role in promoting the growth and survival of myofibroblasts in all types of fibrotic diseases (Andrews et al. 2016).

Recombinant epidermal growth factor rhEGF has been found to play a role in the prevention of scar formation post thyroidectomy. Vancouver Scar Scale (VSS) has been suggested to measure the quality of the scar. Twenty-two patients were involved in the study for evaluation of visible effects like scar, erythema, pigmentation, elasticity, and hydration. And it was found that there was not much difference reported among the patients (Akita et al. 2007). After 4 weeks of follow-up treatment, the pliability score was found to be significantly lowered. So, it can be said that rhEGF successfully

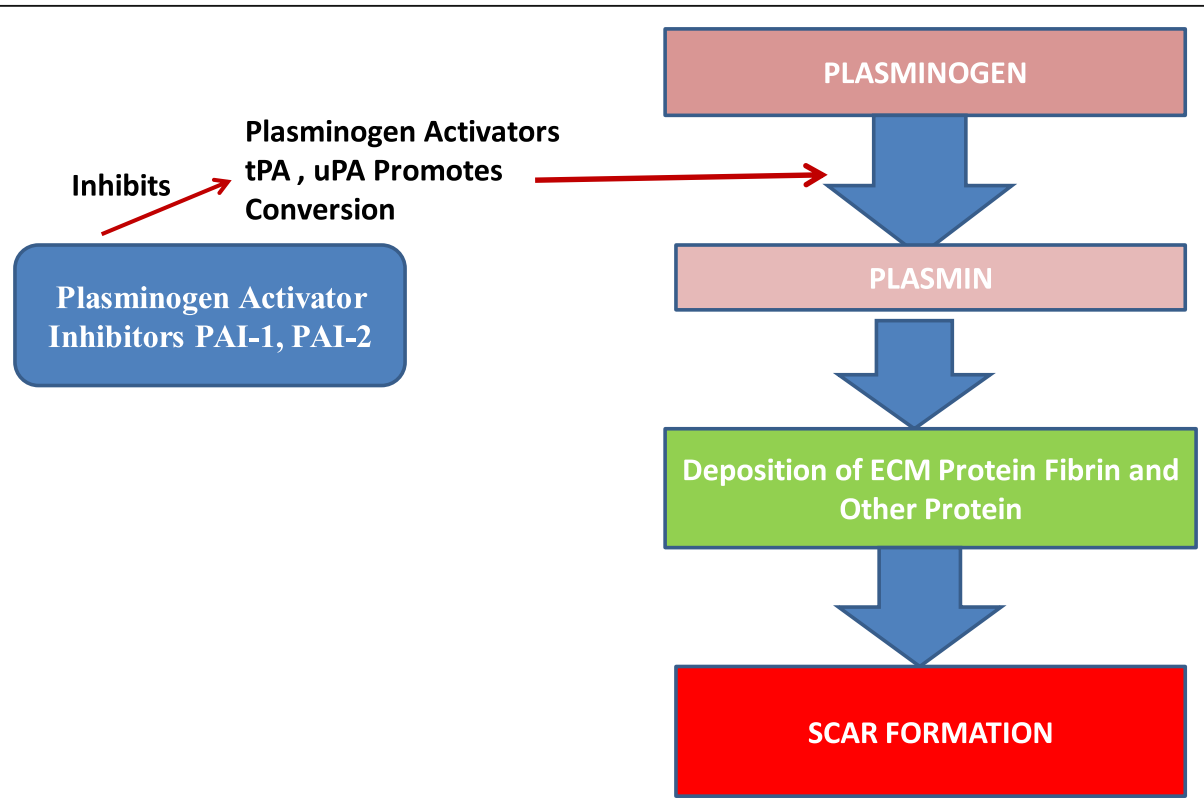

Fig. 2 Role of plasminogen activators and inhibitors 
lowers the VSS score of patients versus the VSS scores of the control group.

CTGF, a cysteine-rich protein, activated in various types of proliferative disorders also plays the role of downstream mediator of TGF- $\beta$ activity that is associated with scar and fibrosis. Colwell et al. hypothesized that there is an increased expression of CTGF by hypertrophic scar and keloid fibroblasts in response to TGF- $\beta$ stimulation (Har-Shai et al. 2003). Baseline CTGF expression was increased 20-fold in unstimulated hypertrophic scar fibroblasts and 15-fold in keloid fibroblasts compared with normal fibroblasts. CTGF expression increased greater than 150-fold when stimulated with TGF- $\beta 1$ and greater than 100 -fold when stimulated by TGF- $\beta 2$ or TGF- $\beta 3$ compared with normal fibroblasts. CTGF expression was greatest after TGF- $\beta 1$ stimulation in hypertrophic scar fibroblasts compared with TGF- $\beta 2$ and TGF- 33 . In keloid fibroblasts, CTGF expression also increased greater than 100-fold after stimulation with TGF- $\beta 1$ and greater than 75 -fold after the addition of TGF- $\beta 2$ and TGF- $\beta 3$ respectively (Colwell et al. 2005).

Epidermal growth factor (EDGF) is a growth factor secreted by platelets, macrophages, and monocytes, and its secretion is stimulated by binding to epidermal growth factor receptor (EGFR) on the cell surface. It acts by stimulating keratinocyte proliferation ligand-induced dimerization and activating the intrinsic protein tyrosine kinase activity of the receptor which in turn initiates a signal cascade resulting in a variety of biochemical changes; thus, it increases keratinocyte proliferation and alter fibroblast activity and decreases inflammatory cell infiltration and TGF- $\beta$ expression in wound healing, resulting in reduced healing time and thickness of scar (Jagadeesan and Bayat 2007).

Histopathological examination revealed the role of VEGF in HTS formation as a remarkable resolver of the nodular arrangement of collagen therapy, and there is a significant difference found in VEGF expression before therapy and controls. Therefore, inhibition of VEGF and anti-angiogenic therapy may be the most promising treatment strategies for the prevention of HTS. Furthermore, VEGF was dynamically correlated with the progression of HTS, because the VEGF level was high in early scars, peaked in proliferative scars, and decreased in regressive scars (Uchida et al. 2003).

\section{Endocrinological hypothesis of HTS}

Endocrinology based theories suggest that the sebaceous gland also takes part in HTS. The sebum or sebocyte's participation is particularly most attractive as it explains about the distribution and behavior of keloids. On onehalf keloid are basically found absent in areas that lack sebaceous glands, such as the palms and soles, and HTS is also reported rarely in animals that lack sebaceous glands. Moreover, sebum production is highly active during teenage and early adulthood and so is considered as the most susceptible period for high incidences of keloids (Mehta et al. 2016).

\section{Role of high-mobility group box protein-1 in HTS}

High-mobility group box protein-1 (HMGB-1), an extracellular mediator, acts as a potent inflammatory cytokine actively released by stimulated monocytes and macrophages by necrotic/damaged cells. Effects of HMGB-1 are displayed on its binding to cell surface receptors (on keratinocytes and fibroblasts), particularly to the RAGE (Receptor for Advanced Glycation End-products) and thus activating the MEK1/2, which then activates ERK1/ 2 and translocates to the nucleus, where it probably alters the gene expression, increases viability, migration, and proliferation of keratinocytes and fibroblasts. So, it can be suggested that HMGB-1 on fibroblasts has a profibrotic role and is partially responsible for excessive scarrings (Lee et al. 2015).

\section{Current available treatments for HTS and keloids}

HTS is difficult to manage and remains a therapeutic challenge for all researchers. No evidence-based literature or universally accepted treatment regimen has been reported to guide their management. Our aim in this review is to present the modern available therapies and their mechanism of action for keloids and HTS mitigation.

\section{Surgery \\ Excision}

Excision may be used to treat keloids alone but often requires administration of adjuvants like radiation or topical drug therapy. Surgical removal may include full excision of the lesion with primary, left to heal by secondary intention. Sutures less inflammatory are preferred in a way, which reduces dead space, foreign material, and risk of infection. Overall, recurrence rates for surgical excision as sole treatment modality range from 45 to $100 \%$, and in one study of 43 subjects that underwent surgical excision of ear keloids, $51.2 \%$ had a recurrence after a year (Berman et al. 2017). Recurrence rates were found to be reduced to almost null range from 0 to $8.6 \%$ when it involved the use of adjuvant radiation therapy after excision (Akita et al. 2007).

\section{Cryosurgery}

Therapeutic management of HTS and keloids using contact or spray cryosurgery has been reported in a number of reviews yielding significant improvement or complete regression of HTS and keloids, in one to 20 treatment sessions. Increased efficacy with intralesional needle cryoprobe method had been reported by scientists due to expanded freezing area of deep scar materials 
compared with that obtained from contact/spray probes. As a result, fewer treatment cycles were needed. Because the reepithelialization period was shortened to 2 to 3 weeks. This intralesional cryoneedle method was simple to operate and safe to use, it necessitates less postoperative care of the wound, and it can easily be added to any preexisting cryosurgical unit (Har-Shai et al. 2003).

\section{Radiation therapy}

Radiation therapy is one of the most popular adjuvant treatment of HTS, incorporating laser beam, and light therapy enhancing the patient compliance and clinician ability to reduce the hypertrophic scar and keloid size with a very low chance of recurrence after surgery or excision.

Mechanism of action of radiation therapy remains under speculations for its treatment providing results. But far and now, it has been reported that it may reduce the scar size by inhibition of reproduction of fibroblasts after surgery, modulating the humeral and cellular factors which stimulate the production of fibroblasts (Keeling et al. 2015). In vitro, it has been shown to inhibit proliferation and induce senescence of keloidal fibroblasts by interrupting cell cycle (Xu et al. 2017). This mechanism was further confirmed by the upregulation of senescence-associated genes, including $\mathrm{p} 21, \mathrm{p} 16$, and $\mathrm{p} 27$.

Radiation therapy for keloids has been studied both as external beam therapy or brachytherapy. External beam radiation typically requires a higher dose due to an increased distance between the source of radiation and the scar, and unaffected normal skin is sometimes exposed to radiation (van Leeuwen et al. 2015). Brachytherapy (or interstitial or internal radiation) differs from external beam radiation in that a catheter is incorporated into the lesion through which the radioactive source is directed, leading to more targeted treatment. Brachytherapy can be administered as low-dose-rate (LDR) or high-dose-rate (HDR), though LDR typically requires longer treatment periods, inpatient hospitalization, and therefore, is not as practical for treatment of benign conditions.

Lee reported the use of postoperative electron beam radiotherapy for keloids and HTS and analyzed the possible risk factor in recurrence. A total of 37 lesions were studied, and an adequate dose of radiation therapy was applied with a $6-\mathrm{MeV}$ electron on the surface of the skin. They found that recurrence-free success rate was $81 \%$. Out of 37 lesions, only 7 reoccured, so it can be concluded that postoperative electron beam radiotherapy can be regarded as an effective treatment method for the prevention of keloid recurrence without serious adverse events. However, radiation therapy should be initiated within $72 \mathrm{~h}$ after surgical excision to prevent recurrence (Lee and Park 2015).

The effectiveness of pulsed dye laser vs pulsed dye laser combined with ultra pulse fractional $\mathrm{CO}_{2}$ laser had been reported by Ouyang et al. were a low-dose-rate total of 56 patients were involved in the study. The treatment group was treated with ultra pulsed dye laser combined with fractional $\mathrm{CO}_{2}$ laser, and the control group was treated with only pulsed dye laser. The above study indicated pulsed dye combined with fractional laser is more effective than pulsed dye laser on the basis of changes assessed in pigment, height, vascularity, and pliability using the Vancouver Scar Scale (VSS) after the two laser treatments (Ouyang et al. 2018).

Radiation therapy is not recommended for pregnant patients, patients less than 12 years old, or for treatment of keloids in radiosensitive locations (such as the thyroid). The development of radiation-induced malignancy stands as one concern for radiation treatment. But overall, evidences suggest that the risk of radiation-induced cancer for benign disease (and therefore, for diseases treated with low-dose radiation) as in the case of keloids is small (McKeown et al. 2015).

\section{Therapeutically active drugs based therapies Verapamil}

Verapamil has a great capacity to control the biosynthesis and formation of the extracellular matrix and has been successfully used for treating keloids and HTS. Recently, it is reported that verapamil can improve the physical texture of keloids and HTS and have been associated with a lower incidence of reoccurrence and reduce the adverse effects, compared with conventional corticosteroid injections (Kumar and Ghosh 2017).

Mechanism of action Verapamil is a calcium channel antagonist that acts significantly on the L-type calcium channels present in the cell plasma membrane, blocking the influx of calcium ions from the extracellular matrix to the cytoplasm. Via its mechanism, verapamil inhibits interleukin 6 (IL-6), vascular endothelial growth factor (VEGF), and fibroblast cell proliferation. It also reduces the expression of transforming growth factor-beta 1 (TGF- $\beta 1$ ), subsequently increases apoptosis.

\section{Silicone gel}

Silicone gel is transparent, self-drying gel applied topically containing long-chain (polysiloxanes), silicone dioxide, and volatile components responsible for improving the appearance of HTS and prevent the scar formation (Manosroi et al. 2013).

Mechanism of action Silicone reduced the collagen production and regulates fibroblast production through hydration of the stratum corneum; thus, it makes scars softer and flattens. Hydration of keratinocytes has a regulatory effect on the metabolism of the underlying fibroblasts resulting in reduced collagen deposition (Wang 
et al. 2016). Silicone gel also works as a modulator of expression of growth factors, fibroblast growth factor $\beta$ (FGF $\beta$ ), and tumor growth factor $\beta$ (TGF $\beta$ ). TGF $\beta$ activates fibroblasts to synthesize collagen and fibronectin. FGF $\beta$ homogenizes the collagen formation in an abnormal scar and increases the level of collagenases which breaks down the excess collagen (Puri and Talwar 2009).

\section{Corticosteroids}

In HTS and keloid, many corticosteroids are used, including hydrocortisone acetate, methylprednisolone, and dexamethasone but most commonly use of triamcinolone acetate as intralesional injection had been shown.

Mechanism of action Triamcinolone acetonide decreased both cellular proliferation and collagen production by dermal fibroblasts. It demonstrated that triamcinolone increases the production of basic fibroblast growth factor (bFGF) and decreases the level of transforming growth factor (TGF $\beta$ ) (Tandara and Mustoe 2008).

Steroid tape plasters have been suggested by (Ogawa et al. 2016). for pediatric and older patients because they have much thinner skin, facilitating steroids easy absorption. A 9-year-old boy with mild right scapular keloids was treated with fludroxycortide tape (Drenison ${ }^{\circ}$ tape). And a change in keloids structure was noted initially, after 16 months, 26 months of treatment. The tape was placed on the keloid $24 \mathrm{~h}$ a day was changed daily. The inflammation resolved completely. After 26 months of treatment, both the subjective and objective symptoms of the patient had improved dramatically (Wang et al. 2016). It would be suggested that corticosteroid tape/ plasters could be used preferentially, on their own or in combination with other therapies such as corticosteroid injection for adults with minor keloids. Notably, the postoperative application of corticosteroid tape/plasters significantly prevents the development of keloids and hypertrophic scars after surgery.

\section{Statins}

Statins are 3-hydroxy-3-methylglutaryl-coenzyme A reductase inhibitor lowers the blood cholesterol level and low-density lipoprotein (Carroll et al. 2002). The use of statins in rabbit scars model wounds was injected with simvastatin, lovastatin, or pravastatin at low, medium, or high doses. Low dose statins are most effective in reducing scars (Ko et al. 2012).

Mechanism of action Statins showed antifibrotic properties in various models of fibrosis in the heart, lung, kidney, intestine, blood vessel, skin, and eye. In vitro studies have demonstrated that the antifibrotic effects of statins are significantly more specifically to their ability to downregulate expression of connective tissue growth factor (CTGF) which is a major profibrotic mediator that acts downstream of, and in concert with, TGF- $\beta$ to drive fibrogenesis (Ko, Kim et al. 2012). Statins have been shown to inhibit connective tissue growth factor (CTGF) gene and protein expression, thus inhibiting the HTS (Watts and Spiteri 2004).

\section{5-Fluorouracil (5-FU)}

The use of 5-FU intralesional injection, in HTS and keloids both as individual therapy as well as in combination with corticosteroids, has been found to be more effective and painless (Fitzpatrick 1999).

Mechanism of action 5-FU, a pyrimidine analog with antimetabolite activity, inhibits proliferation and myofibroblast differentiation in dupuytren fibroblasts. 5-FU rapidly targets proliferating and metabolizing fibroblasts in dermal wounds liable for excessive collagen production (Chen and Davidson 2005).

\section{Bleomycin}

It is a polypeptide antibiotic possessing potent antitumor, antibacterial, and antiviral activity also used to treat HTS and keloids (Reddy et al. 2015). The effectiveness of bleomycin in HTS was demonstrated through a clinical trial involving 20 patients with HTS and keloids. Out of 20 patients, 13 (65\%) showed excellent response, and there was a complete resolution of symptoms in 11 patients.

Mechanism of action The exact mechanism of action by which bleomycin treat keloids and the hypertrophic scar is still in elucidated. Some study elaborated that it inhibits collagen synthesis stimulated by transforming growth factor-beta 1, which expressed a high level in scar tissue. Bleomycin also reduces collagen synthesis which may be due to a reduction in lysyl oxidase levels which is important for collagen maturation (Saray and Gulec 2005).

\section{Mitomycin C}

It is an antibiotic produced by Streptomyces caespitosus used as a chemotherapeutic agent inhibiting DNA synthesis in neoplastic cells. At high doses, it can inhibit RNA and protein synthesis also (Yeowell et al. 1994). The topical and intralesional efficacy of mitomycin C in HTS and keloids was checked via study performed on total 9 patients involved in the clinical trials for 6 months used $1 \mathrm{mg} / \mathrm{mL}$ mitomycin topically for $3 \mathrm{~min}$ after excision and 2 patient treated with $1 \mathrm{mg} / \mathrm{mL}$ mitomycin $\mathrm{C}$ intralesionally. Six patient out of 9 are very satisfied with the result of the treatment; none were disappointed. On the other hand, the results of intralesional mitomycin $C$ were disappointing and led to the worsening of both cases (Seo and Sung 2012). 


\section{Paclitaxel}

The efficacy and therapeutic response of paclitaxel in the treatment of HTS on the rabbit ears model had been reported. The study involved preparation of the dosage of paclitaxel in different concentration ranges $(12 \mathrm{mg} / \mathrm{L}, 24$ $\mathrm{mg} / \mathrm{L}, 48 \mathrm{mg} / \mathrm{L}, 96 \mathrm{mg} / \mathrm{L}, 18 \mathrm{mg} / \mathrm{L}, 54 \mathrm{mg} / \mathrm{L}, 162 \mathrm{mg} / \mathrm{L}$, $486 \mathrm{mg} / \mathrm{L}, 30 \mathrm{mg} / \mathrm{L}, \quad 150 \mathrm{mg} / \mathrm{L}, 750 \mathrm{mg} / \mathrm{L}, 3,750 \mathrm{mg} / \mathrm{L}$ ). The time of injecting drugs was 28th days after wounding when hypertrophic scar formation was on peak. Ten days after injection, results showed that in comparison of the control group, the paclitaxel in the concentration range $96 \mathrm{mg} / \mathrm{L}, 150 \mathrm{mg} / \mathrm{L}$, and $162 \mathrm{mg} / \mathrm{L}$ reduced the formation of a scar; however, in higher concentration, $>400 \mathrm{mg} / \mathrm{L}$ local tissue necrosis occurred (Huang et al. 2015).

\section{Topical novel drug delivery systems (DDS) for the treatment of HTS and keloids}

Topical drug delivery systems, in particular, have become increasingly popular because of their ease of use, comfort, noninvasiveness, and relatively low cost. Topical drug delivery systems have received increasing importance because of their fewer side effects and longterm suppression in HTS and keloids.

\section{Ethosome transethosomes and transferosomal drug delivery}

In transdermal drug delivery of HTS and keloid, the major obstacle is the stratum corneum. Hence, for the effective treatment of HTS and in order to increase the efficiency of anti-scarring agent, a high-performance vesicular carrier system was required. Ethosome and transethosomes can be opted because of their good profusing property can be used for sufficient local concentration of drug in the site of scars. The major characteristics of ethosomal drug delivery are their deformability. Hence, they can penetrate the skin pores 5-10 times lesser than their own size and ultraefficient for both high molecular and low molecular drugs (Gauglitz et al. 2011a, 2011b). Two significant features of ethosomes that improve cutaneous drug absorption are first, the presence of ethanol in ethosomes as penetration enhancer increase penetration by increasing cell membrane lipid fluidity and thus reducing epidermal membrane density, and secondly highly soft, malleable ethosome facilitates deep cutaneous penetration.

The effective use of ethosomal gel of 5-FU in HTS was measured in the rabbit ear model. The relative thickness of rabbit scars was measured by the caliper scale before and after treatment. The morphology of the rabbit ear was compared for hypertrophic scar determination using a $\mathrm{CO}_{2}$ fractional laser. After 7 days of treatment in these four groups on rabbit ears having HTS, it was found that only 5-FU ethosomal gel and $\mathrm{CO}_{2}$ fractional laser treated groups showed the decreased dermal layer thickness of HTS (Zhang et al. 2016).

\section{Hydrogel}

The hydrogel is a cluster of macromolecular polymeric structures capable of holding a large quantity of water (Matiasek et al. 2018). The use of an octenidine-based hydrogel in HTS has been reported. Octenidine-based hydrogel modulates immunological functions in an in vitro wound model. They demonstrated their study over 45 patients who had undergone abdominoplasty or mastectomy with transverse rectus abdominis muscle (TRAM). Both standard dressing and a hydrogel-based dressing were used in all 45 patients. Vancouver Scar Scale (VSS) scores showed improvement in the scar size of those treated with the gel side after 3, 6, and 12 months postoperative (Danielson and Walter 2005). A hydrogel-based topical formulation combining $2 \%$ salicylic acid had also been reported with treatment protocol for 60 days. Here, patients were categorized for treatment in 3 groups and were exposed followingly: group I control (no treatment), and group II was given hydrogel formulation treatment without the drug. After 60 days of treatment, it was found that the area treated with $2 \%$ salicylic acid was found asymatomatic, and untreated control areas remained erythematous and symptomatic for burning pain and pruritus.

\section{Solid lipid nanoparticles}

Solid lipid nanoparticles (SLNs) are colloidal carrier systems emerging as innovative and promising alternatives in the last decade with improved therapeutic effectiveness and minimized undesirable side effects associated with drugs (Chen et al. 2013). The SLN-enriched hydrogel (SLNgel) of astragaloside IV, a poorly water-soluble drug, was found to release drugs sustainably and increased the migration and proliferation of keratinocytes and increased the drug uptake in fibroblasts.

\section{Liposomes}

Liposomes are a spherical-shaped vehicles with a selfclosed membrane formed by one or several concentric lipid bilayers, compatible with both hydrophilic and hydrophobic drugs. Many studies have proved the therapeutic efficacy, efficacy, and safety profile of liposomal drug delivery in HTS and keloid (Akbarzadeh et al. 2013). A study over 24 months was conducted among the patient of HTS and keloids. Patients were divided into two categories: first, group A patients were treated with intralesional injection of bleomycin; group B was treated with liposomal drug delivery of bleomycin. It was found that only $80.11 \%$ scars were reduced in size in group A whereas $90.17 \%$ reduction in the size of scars was reported in group B. This showed that liposomal 
drug delivery of bleomycin significantly gave the better result and less adverse effects.

\section{Microspheres}

Microspheres are small spherical multiparticulate drug delivery systems, with a diameter 1 to $1000 \mu \mathrm{m}$. Microspheres can be manufactured from various natural and synthetic materials. Microspheres enhance the bioavailabilty, stability, and efficacy of conventional drugs and minimize the side effects. Porous microspheres of poorly water-soluble drugs like asiaticoside showed an enhancement in the cellular uptake of asiaticoside. It was reported that asiaticoside-microspheres showed promising regenerative healing and anti-scar effects for wound therapy by enhancing reepithelization, regulating the synthesis, and disposition of different types of collagens, as well as stimulating angiogenesis. Asiaticoside embedded in these microspheres could release the drug in a sustained manner (Gauglitz et al. 2011a, 2011b).

\section{Microsponges}

The use of silver sulfadiazine loaded microsponges based gel in burn wounds had been in practice. It has been reported that microsponge delayed the release of a drug. Slow release of a drug from the microsponges reduced the frequency of application and chances of scar formation, enhancing the efficacy and reducing the cytotoxicity towards the keratinocytes and fibroblasts without altering the antimicrobial properties of drug (Kumar and Ghosh 2017).

\section{Niosomes}

The penetration and efficacy of papain from gel formulations containing niosomes and nanospheres loaded with papain in the rabbit ear scar model was compared. The vesicular sizes of niosomes and nanospheres in the gel formulations were in the range of $221-520 \mathrm{~nm}$ (Zhang et al. 2016). Three formulations were prepared namely papain loaded in elastic niosomes (GEN), a second gel containing free papain (GS), and gel containing papain loaded in non-elastic niosomes (GNN). After 28 days of therapy, they found that the numbers of collagen fibers and the height of the scars treated with papain loaded in elastic niosomes (GEN) were significantly decreased compared with the control group.

\section{Conclusion}

With the surfeit availability of potential treatments available and on the basis of published evidences for HTS and keloids, it has been deduced that combined therapy is more effective than individual drug therapy. International guidelines for the treatment of scars published by Gold and colleagues (Gold, McGuire et al. 2014) present a systematic algorithm for the mitigation of keloids and HTS. This review tries to shed light on pharmaceutical approaches adapted in commutive treatments of HTS and keloids along with prerequisite surgical and radiation therapies. Gold et al. suggested that for a minor keloid, the primary treatment to consider is silicone gel/sheeting with intralesional corticosteroids, followed by fractional or pulsed dye laser, and if the lesions remain refractory, progress to surgical excision with various topical therapies including silicone gel/sheeting, intralesional steroids, radiotherapy, or alternative therapies (bleomycin, mitomycin, and imiquimod). For larger keloids or HTS, they recommend intralesional steroids, followed by intralesional 5-FU with steroids, and then progressing to the fractional or pulsed dye laser, and if the lesions remain refractory, surgical excision with topical drug delivery systems (mentioned above). Topical combined treatment approach being noninvasive, relatively safer, convenient, and cheaper is found to be helpful as an adjuvant to surgery or radiotherapy.

\section{Acknowledgements \\ Not applicable.}

\section{Authors' contributions}

(Sanjeev Tripathi) ST contributed in how abnormal wound healing promoted HTS and keloids. (Kumud Soni) KS contributed in figures. (Poornima Agrawal) PA contributed in basic conceptualization and current treatments available for HTS and keloids. (Vishal Gour) VG contributed in various studies related data. (Corresponding Author) (Prof. Vandana Soni) VS and (Rajesh Mondal) RM reviewed the entire manuscript. All authors read and approved the final manuscript, conceived this review, analyzed the scientific literature, and critically discussed the perspectives concerning the subject of the review.

\section{Funding}

No fundings have been used to write this review.

\section{Availability of data and materials}

No further supporting data have been used besides those reported in this manuscript.

Ethics approval and consent to participate Not applicable.

\section{Consent for publication}

The consent form is held by the author and is available for review by the Editor-in-Chief.

\section{Competing interests}

The author declares that there are no competing interests.

\section{Author details}

${ }^{1}$ Department of Pharmaceutical Sciences, Dr. Harisingh Gour University, Sagar 470 003, (M.P.), India. ²Deptartment of Bacteriology, ICMR-National Institute for Research in Tuberculosis, No.1 Mayer Ramanathan Road, Chennai-31, India.

Received: 20 December 2019 Accepted: 12 March 2020

Published online: 20 May 2020

\section{References}

Akbarzadeh A, Rezaei-Sadabady R, Davaran S, Joo SW, Zarghami N, Hanifehpour Y, Samiei M, Kouhi M, Nejati-Koshki K. Liposome: classification, preparation, and applications. Nanoscale Res Lett. 2013;8(1):102. 
Akita S, Akino K, Yakabe A, Imaizumi T, Tanaka K, Anraku K, Yano H, Hirano A. Combined surgical excision and radiation therapy for keloid treatment. J Craniofac Surg. 2007;18(5):1164-9.

Andrews JP, Marttala J, Macarak E, Rosenbloom J, Uitto J. Keloids: the paradigm of skin fibrosis - pathomechanisms and treatment. Matrix Biology. 2016;51: 37-46.

Berman B, Maderal A, Raphael B. Keloids and hypertrophic scars: pathophysiology, classification, and treatment. Dermatol Surg. 2017:43(Suppl 1):S3-S18.

Carroll LA, Hanasono MM, Mikulec AA, Kita M, Koch RJ. Triamcinolone stimulates bFGF production and inhibits TGF- $\beta 1$ production by human dermal fibroblasts. Dermatologic Surg. 2002;28(8):704-9.

Chen MA, Davidson TM. Scar management: prevention and treatment strategies. Curr Opin Otolaryngol Head Neck Surg. 2005;13(4):242-7.

Chen X, Peng LH, Shan YH, Li N, Wei W, Yu L, Li QM, Liang WQ, Gao JQ. Astragaloside IV-loaded nanoparticle-enriched hydrogel induces wound healing and anti-scar activity through topical delivery. Int J Pharm. 2013; 447(1-2):171-81.

Colwell AS, Phan T-T, Kong W, Longaker MT, Lorenz PH. Hypertrophic scar fibroblasts have increased connective tissue growth factor expression after transforming growth factor- $\beta$ stimulation. Plastic Reconstructive Surg. 2005; 116(5):1387-90

Danielson JR, Walter RJ. Case studies: use of salicylic acid (Avosil) and hydrogel (Avogel) in limiting scar formation. J Burns Wounds. 2005;4 https://www.ncbi. nlm.nih.gov/pmc/articles/PMC1501120/) (PMID:16921411.

Ehrlich HP, Krummel TM. Regulation of wound healing from a connective tissue perspective. Wound Repair Regen. 1996;4(2):203-10.

Fitzpatrick RE. Treatment of inflamed hypertrophic scars using intralesional 5-FU. Dermatologic Surg. 1999;25(3):224-32.

Gale AJ. Continuing education course\# 2: current understanding of hemostasis. Toxicol Pathol. 2011;39(1):273-80.

Gauglitz GG, Korting HC, Pavicic T, Ruzicka T, Jeschke MG. Hypertrophic scarring and keloids: pathomechanisms and current and emerging treatment strategies. Mol Med. 2011a;17(1):113.

Gauglitz GG, Korting HC, Pavicic T, Ruzicka T, Jeschke MG. Hypertrophic scarring and keloids: pathomechanisms and current and emerging treatment strategies. Mol Med. 2011b;17(1-2):113-25.

Ghazawi FM, Zargham R, Gilardino MS, Sasseville D, Jafarian F. Insights into the pathophysiology of hypertrophic scars and keloids: how do they differ? Adv Skin Wound Care. 2018;31(1):582-95.

Gold MH, McGuire M, Mustoe TA, Pusic A, Sachdev M, Waibel J, Murcia C, M. International Advisory Panel on Scar. Updated international clinical recommendations on scar management: part 2--algorithms for scar prevention and treatment. Dermatol Surg. 2014;40(8):825-31.

Gong ZH, Ji JF, Yang J, Xiang T, Zhou CK, Pan XL, Yao J. Association of plasminogen activator inhibitor-1 and vitamin $D$ receptor expression with the risk of keloid disease in a Chinese population. Kaohsiung J Med Sci. 2017; 33(1):24-9.

Har-Shai Y, Amar M, Sabo E. Intralesional cryotherapy for enhancing the involution of hypertrophic scars and keloids. Plast Reconstr Surg. 2003;111(6): 1841-52.

Huang LP, Wang GQ, Jia ZS, Chen JW, Wang G, Wang XL. Paclitaxel reduces formation of hypertrophic scars in the rabbit ear model. Ther Clin Risk Manag. 2015;11:1089-95.

Jagadeesan J, Bayat A. Transforming growth factor beta (TGF $\beta$ ) and keloid disease. Int J Surg. 2007:5(4):278-85.

Jester JV, Nien CJ, Vasiliou V, Brown DJ. Quiescent keratocytes fail to repair MMC induced DNA damage leading to the long-term inhibition of myofibroblast differentiation and wound healing. Mol Vis. 2012;18:1828-39.

Keeling BH, Whitsitt J, Liu A, Dunnick CA. Keloid removal by shave excision with adjuvant external beam radiation therapy. Dermatol Surg. 2015;41(8):989-92.

Ko JH, Kim PS, Zhao Y, Hong SJ, Mustoe TA. HMG-CoA reductase inhibitors (statins) reduce hypertrophic scar formation in a rabbit ear wounding model. Plast Reconstr Surg. 2012;129(2):252e-61e.

Kuehlmann B, Stern-Buchbinder Z, Wan DC, Friedstat JS, Gurtner GC. Beneath the surface: a review of laser remodeling of hypertrophic scars and burns. Adv Wound Care. 2019:8(4):168-76.

Kumar PM, Ghosh A. Development and evaluation of silver sulfadiazine loaded microsponge based gel for partial thickness (second degree) burn wounds. Eur J Pharm Sci. 2017:96:243-54.
Lee DE, Trowbridge RM, Ayoub NT, Agrawal DK. High-mobility group box protein-1, matrix metalloproteinases, and vitamin D in keloids and hypertrophic scars. Plast Reconstr Surg Glob Open. 2015;3(6):e425.

Lee SY, Park J. Postoperative electron beam radiotherapy for keloids: treatment outcome and factors associated with occurrence and recurrence. Ann Dermatol. 2015;27(1):53-8.

Lichtman MK, Otero-Vinas M, Falanga V. Transforming growth factor beta (TGF- $\beta$ ) isoforms in wound healing and fibrosis. Wound Repair and Regeneration. 2016;24(2):215-22.

Manosroi A, Chankhampan C, Manosroi W, Manosroi J. Transdermal absorption enhancement of papain loaded in elastic niosomes incorporated in gel for scar treatment. Eur J Pharm Sci. 2013;48(3):474-83.

Matiasek J, Kienzl P, Unger LW, Grill C, Koller R, Turk BR. An intra-individual surgical wound comparison shows that octenidine-based hydrogel wound dressing ameliorates scar appearance following abdominoplasty. Int Wound J. 2018;15(6):914-20.

McKeown SR, Hatfield P, Prestwich RJ, Shaffer RE, Taylor RE. Radiotherapy for benign disease; assessing the risk of radiation-induced cancer following exposure to intermediate dose radiation. Br J Radiol. 2015;88(1056):20150405.

Mehta M, Branford OA, Rolfe KJ. The evidence for natural therapeutics as potential anti-scarring agents in burn-related scarring. Burns Trauma. 2016:4(1):15.

Miller M-C, Nanchahal J. Advances in the modulation of cutaneous wound healing and scarring. Bio Drugs. 2005;19(6):363-81.

Ogawa R, Akaishi S, Kuribayashi S, Miyashita T. Keloids and hypertrophic scars can now be cured completely: recent progress in our understanding of the pathogenesis of keloids and hypertrophic scars and the most promising current therapeutic strategy. J Nippon Med School. 2016;83(2):46-53.

Ouyang HW, Li GF, Lei Y, Gold MH, Tan J. Comparison of the effectiveness of pulsed dye laser vs pulsed dye laser combined with ultrapulse fractional CO 2 laser in the treatment of immature red hypertrophic scars. J Cosmetic Dermatol. 2018;17(1):54-60

Puri N, Talwar A. The efficacy of silicone gel for the treatment of hypertrophic scars and keloids. J Cutan Aesthet Surg. 2009;2(2):104-6.

Reddy $\mathrm{R}$, Harinatha S, Raghunath $\mathrm{N}$. The role of bleomycin in management of hypertrophic scars and keloids-a clinical trial. Our Dermatol Online. 2015;6(4):404.

Santucci M, Borgognoni L, Reali UM, Gabbiani G. Keloids and hypertrophic scars of Caucasians show distinctive morphologic and immunophenotypic profiles. Virchows Archiv. 2001;438(5):457-63.

Saray Y, Gulec AT. Treatment of keloids and hypertrophic scars with dermojet injections of bleomycin: a preliminary study. Int J Dermatol. 2005;44(9):777-84.

Seo SH, Sung HW. Treatment of keloids and hypertrophic scars using topical and intralesional mitomycin C. J Eur Acad Dermatol Venereol. 2012;26(5):634-8.

Shaffer JJ, Taylor SC, Cook-Bolden F. Keloidal scars: a review with a critical look at therapeutic options. J Am Acad Dermatol. 2002;46(2):S63-97.

Shin JU, Kang SW, Jeong JJ, Nam KH, Chung WY, Lee JH. Effect of recombinant human epidermal growth factor on cutaneous scar quality in thyroidectomy patients. J Dermatolog Treat. 2015;26(2):159-64.

Shi-Wen X, Leask A, Abraham D. Regulation and function of connective tissue growth factor/CCN2 in tissue repair, scarring and fibrosis. Cytokine Growth Factor Rev. 2008;19(2):133-44.

Tandara AA, Mustoe TA. The role of the epidermis in the control of scarring: evidence for mechanism of action for silicone gel. J Plast Reconstr Aesthet Surg. 2008:61(10):1219-25.

Tanriverdi-Akhisaroglu S, Menderes A, Oktay G. Matrix metalloproteinase-2 and-9 activities in human keloids, hypertrophic and atrophic scars: a pilot study. Cell Biochem Funct. 2009;27(2):81-7 https://onlinelibrary.wiley.com/doi/abs/1 0.1002/cbf.1537) (https://doi.org/10.1002/cbf.1537.

Tuan T-L, Nichter LS. The molecular basis of keloid and hypertrophic scar formation. Mol Med Today. 1998:4(1):19-24.

Uchida G, Yoshimura K, Kitano Y, Okazaki M, Harii K. Tretinoin reverses upregulation of matrix metalloproteinase-13 in human keloid-derived fibroblasts. Exp Dermatol. 2003;12:35-42.

van Leeuwen MC, Stokmans SC, Bulstra AE, Meijer OW, Heymans MW, Ket JC, Ritt MJ, van Leeuwen PA, Niessen FB. Surgical excision with adjuvant irradiation for treatment of keloid scars: a systematic review. Plast Reconstr Surg Glob Open. 2015;3(7):e440

Velnar T, Bailey T, Smrkolj V. The wound healing process: an overview of the cellular and molecular mechanisms. J Int Med Res. 2009:37(5):1528-42.

Wang R, Mao Y, Zhang Z, Li Z, Chen J, Cen Y. Role of verapamil in preventing and treating hypertrophic scars and keloids. Int Wound J. 2016;13(4):461-8. 
Watts KL, Spiteri MA. Connective tissue growth factor expression and induction by transforming growth factor $\beta$ is abrogated by simvastatin via a Rho signaling mechanism. Am J Physiol Lung Cell Mol Physiol. 2004;287(6):L1323-32.

Wu WS, Wang FS, Yang KD, Huang CC, Kuo YR. Dexamethasone induction of keloid regression through effective suppression of VEGF expression and keloid fibroblast proliferation. J Invest Dermatol. 2006;126(6):1264-71.

Xu, J., E. Yang, N.-Z. Yu, Y.-B. Wang and X. Long (2017). "The radiation therapy in keloids treatment: a comprehensive review of pathomechanism, damage mechanisms and cellular response." ((10.20517/2347-9264.2017.24) (https:// parjournal.net/article/view/2166)).

Yates CC, Hebda P, Wells A. Skin wound healing and scarring: fetal wounds and regenerative restitution. Birth Defects Res C Embryo Today. 2012;96(4):325-33.

Yeowell HN, Marshall MK, Walker LC, Ha V, Pinnell SR. Regulation of lysyl oxidase mRNA in dermal fibroblasts from normal donors and patients with inherited connective tissue disorders. Arch Biochem Biophys. 1994;308(1):299-305.

Zhang CZ, Niu J, Chong YS, Huang YF, Chu Y, Xie SY, Jiang ZH, Peng LH. Porous microspheres as promising vehicles for the topical delivery of poorly soluble asiaticoside accelerate wound healing and inhibit scar formation in vitro \& in vivo. Eur J Pharm Biopharm. 2016;109:1-13.

Zhao D, Wang Y, Du C, Shan S, Zhang Y, Du Z, Han D. Honokiol alleviates hypertrophic scar by targeting transforming growth factor- $\beta / S \operatorname{mad} 2 / 3$ signaling pathway. Front Pharmacol. 2017:8:206.

Zhu Z, Ding J, Tredget EE. The molecular basis of hypertrophic scars. Burns Trauma. 2016;4(1):2.

\section{Publisher's Note}

Springer Nature remains neutral with regard to jurisdictional claims in published maps and institutional affiliations.

Ready to submit your research? Choose BMC and benefit from:

- fast, convenient online submission

- thorough peer review by experienced researchers in your field

- rapid publication on acceptance

- support for research data, including large and complex data types

- gold Open Access which fosters wider collaboration and increased citations

- maximum visibility for your research: over $100 \mathrm{M}$ website views per year

At $\mathrm{BMC}$, research is always in progress.

Learn more biomedcentral.com/submissions 